Check for updates

Cite this: RSC Adv., 2019, 9, 18670

\title{
Novel dermacozine-1-carboxamides as promising anticancer agents with tubulin polymerization inhibitory activity $\dagger$
}

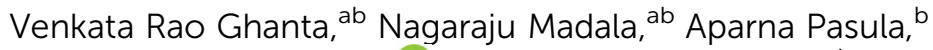
Sai Kiran S. S. Pindiprolu, (D) C Kumara Swamy Battula, ${ }^{\mathrm{d}}$ Praveen T. Krishnamurthy (D) *c and Balamurali Raman*a

In the present study, novel dermacozine-1-carboxamides (8a-8n) were synthesized and screened for their in vitro cytotoxic activity against three different cancer cell lines: MCF-7 (breast cancer), A-549 (lung cancer) and DU145 (prostate cancer). All the compounds showed more efficiency against the DU145 cell line than against the MCF-7 and A-549 cell lines. Furthermore, 8a (CTC $50: 7.02 \mu \mathrm{M})$ and 81 ( CTC $\left._{50}: 6.32 \mu \mathrm{M}\right)$ have been found to be more effective against the DU145 cells as they arrest the cell cycle at the G2/M phase by interfering with tubulin polymerization; these results indicate that these compounds act as potential anti-cancer agents by inhibiting tubulin polymerization.

Received 31st March 2019

Accepted 27th May 2019

DOI: 10.1039/c9ra02416f

rsc.li/rsc-advances

activity, cytotoxicity against the resistant cancer cell line K562 (human chronic myelogenous leukemia), and so on;;,9 moreover, previously, we have reported the first total synthesis of the dermacozine A, B and C. ${ }^{10}$ In the present study, a new series of dermacozine-1-carboxamides $\mathbf{8 a - 8 n}$ was synthesized, and the cytotoxic activity of these compounds as well as their effect on the cell cycle and associated cyclin and tubulin polymerization were investigated to elucidate their possible mechanism of action.

\section{Results and discussion}

\section{Chemistry}

The synthesis of the dermacozine-1-carboxylic acid 7 and its derivatives was achieved in 6 steps, as shown in Scheme $1 .^{10}$ The accounting for various pharmacological activities. ${ }^{5,6}$ Phenazine and fused aryl phenazine derivatives, such as XR11576, XR5944, NC-190 and NC-182, are under clinical studies for their cytotoxic activity. ${ }^{7}$

The dermacozines A-J are a class of reduced phenazine-based marine natural products isolated from Dermacoccus abyssi sp. nov., strains MT1.1 and MT1.2, which are highly pigmented aromatic compounds. These compounds have been reported to exhibit various biological activities such as radical scavenging

${ }^{a}$ GVK Biosciences Private Limited, Medicinal Chemistry Division, 28 A, IDA Nacharam, Hyderabad, Telangana, India. E-mail: balamuraliraman73@gmail.com

${ }^{b}$ Department of Chemistry, Jawaharlal Nehru Technological University, Kukatpally, Hyderabad, Telangana, India

'Department of Pharmacology, JSS College of Pharmacy, JSS Academy of Higher Education \& Research, Ooty, Tamil Nadu, India.E-mail: praveentk7812@gmail.com ${ }^{d}$ Department of Chemistry, Kakatiya University, Warangal-506 009, Telangana, India $\dagger$ Electronic supplementary information (ESI) available. See DOI: $10.1039 / \mathrm{c} 9 \mathrm{ra02416f}$
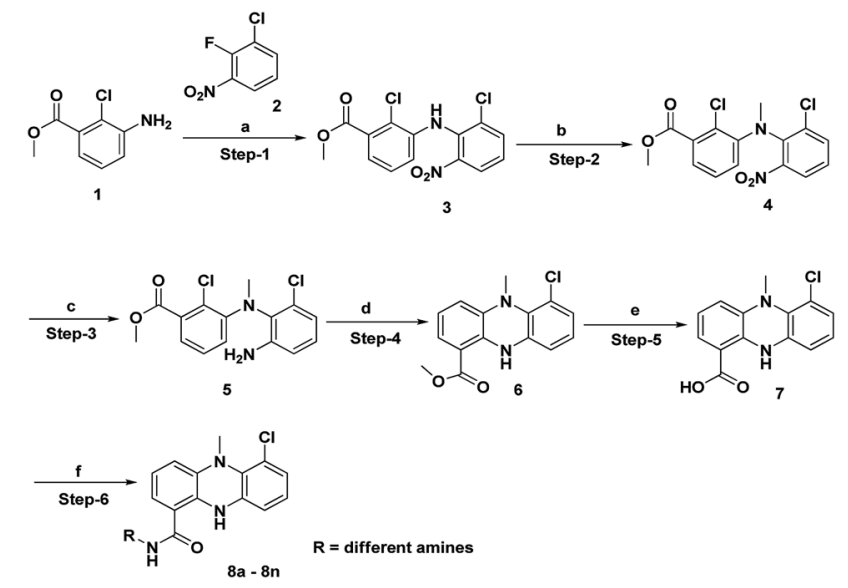

Scheme 1 Synthesis of dermacozine-1-carboxamides. 
commercially available methyl 3-amino-2-chlorobenzoate 1 was treated with 1-chloro-2-fluoro-3-nitrobenzene 2 in the presence of LiHMDS at $-78{ }^{\circ} \mathrm{C}$ to afford the methyl 2-chloro-3-((2-chloro6-nitrophenyl)amino)benzoate $3 .{ }^{11}$ Methylation of 3 with MeI in the presence of $\mathrm{NaOH}$ afforded the $N$-methyl intermediate 4 . Then, the reduction of the nitro group was performed using $\mathrm{Fe}-$ $\mathrm{NH}_{4} \mathrm{Cl}$ at reflux temperature to furnish 5. After this, intramolecular cyclisation of $\mathbf{5}$ was conducted under Buchwald conditions in the presence of Johnphos, $\mathrm{pd}_{2}(\mathrm{dba})_{3}$ and $\mathrm{Cs}_{2} \mathrm{CO}_{3}$, at $120{ }^{\circ} \mathrm{C}$ under sealed conditions. Then, hydrolysis of the methyl ester 6 to the acid 7 was performed using $4 \mathrm{~N} \mathrm{NaOH}$ at room temperature, as shown in Scheme 1. The amide derivatives 8a-8n were synthesized in good yields by treating the acid 7 with 14 different amines using HATU-DIPEA at room temperature (Fig. 1).

The structures of the newly synthesized compounds $\mathbf{8 a}-\mathbf{8 n}$ were confirmed by ${ }^{1} \mathrm{H}-\mathrm{NMR},{ }^{13} \mathrm{C}-\mathrm{NMR}$, FT-IR, ESI-MS and HRMS analysis data. All the spectral and analytical data of the synthesized compounds were in full agreement with the proposed structures and have also been discussed for the derivative 8f. In the ${ }^{1} \mathrm{H}-\mathrm{NMR}$ spectra, the characteristic $\mathrm{N}$ methyl and $\mathrm{NH}$ peaks appeared at $3.22\left(3 \mathrm{H}, \mathrm{s}, \mathrm{NCH}_{3}\right)$ and 9.74 $(1 \mathrm{H}, \mathrm{s}, \mathrm{NH})$, all the aromatic protons appeared in the range of 6.65-9.74 $(11 \mathrm{H}, \mathrm{m}, \mathrm{ArH})$, the amide proton appeared at 8.55 (br s, 1H, CONH) and the alkyl proton exhibited a singlet at 2.84 $\left(2 \mathrm{H}\right.$, br $\left.\mathrm{t}, \mathrm{Ar}-\mathrm{CH}_{2}\right)$ and 3.42-3.51 $\left(2 \mathrm{H}, \mathrm{m}, \mathrm{CONH}-\mathrm{CH}_{2}\right)$, confirming the presence of required protons. In the ${ }^{13} \mathrm{C} N M R$ spectra, the presence of carbon signals at $167 \mathrm{ppm}(\mathrm{C}=\mathrm{O})$, $45 \mathrm{ppm}\left(\mathrm{NCH}_{3}\right), 40 \mathrm{ppm}\left(\mathrm{CONH}-\mathrm{CH}_{2}\right)$ and $34 \mathrm{ppm}\left(\mathrm{Ar}-\mathrm{CH}_{2}\right)$

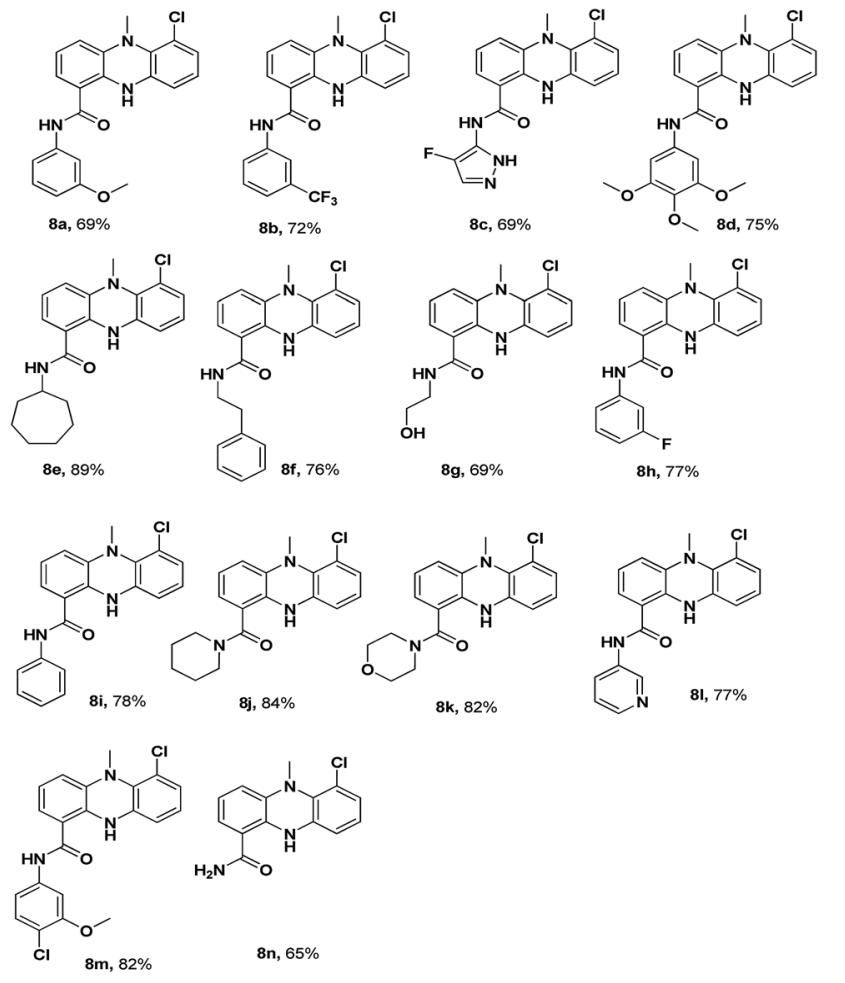

Fig. 1 Structures of dermacozine-1-carboxamides. confirmed the presence of characteristic carbon bonds. In the FT-IR spectra, a strong absorption band was observed at $1629 \mathrm{~cm}^{-1}$, which confirmed the formation of the amide bond $(\mathrm{C}=\mathrm{O}$ stretch). Furthermore, a strong absorption peak was observed at $3373 \mathrm{~cm}^{-1}$, which confirmed the $\mathrm{N}-\mathrm{H}$ bond formation. In the HR-MS of 8f, a peak was found at 378.1367 [M $+\mathrm{H}]^{+}$, which matched the calculated value $378.2137[\mathrm{M}+\mathrm{H}]^{+}$; this confirmed the molecular weight of the compound $8 f$ $\left(\mathrm{C}_{22} \mathrm{H}_{21} \mathrm{ON}_{3} \mathrm{Cl}\right)$.

\section{Biology}

Cytotoxicity. MTT assay was performed to determine the cytotoxicity of the synthesized dermacozine-1-carboxamides against the MCF-7 (breast cancer), A-549 (lung cancer) and DU145 (prostate cancer) cells. The concentrations at which the test compounds inhibited the growth of $50 \%$ of cells $\left(\mathrm{CTC}_{50}\right)$ are presented in Table 1 . The synthesized derivatives $\mathbf{8 a - 8 n}$ were found to be effective in killing the DU145 cells as compared to the case of other cell lines tested herein. Among the various synthesized dermacozine-1-carboxamides, 8a, 8d, 8i, 81 and $\mathbf{8 m}$ were found to be more effective, with the $\mathrm{CTC}_{50}$ values of $7.02 \pm$ $0.54,10.62 \pm 0.77,8.95 \pm 0.77,6.32 \pm 0.68$ and $9.26 \pm 0.57 \mu \mathrm{M}$, respectively. Furthermore, $\mathbf{8 a}\left(\mathrm{CTC}_{50}: 7.02 \mu \mathrm{M}\right)$ and $\mathbf{8 1}\left(\mathrm{CTC}_{50}\right.$ : $6.32 \mu \mathrm{M})$ were selected for mechanistic studies. The derivatives with electron-releasing groups, such as methoxy and chloro, exhibited highest activity as compared to other derivatives.

Structure-activity relationship (SAR). Based on the $\mathrm{CTC}_{50}$ values, we deduced the SAR of the compounds. Via the SAR studies, we speculated that the compounds $\mathbf{8 a - 8 n}$ bearing aryl, hetero aryl, or aliphatic amide groups exhibited significant anticancer activity against the DU145 cell line than against the MCF7 and A549 cell lines. Moreover, the 3-pyridyl amide compound 81 exhibited highest anti-cancer activity than the other phenyl amide derivatives $\mathbf{8 a}, \mathbf{8 b}$, and $\mathbf{8 h}$. Furthermore, the phenyl

Table 1 In vitro anticancer activity of dermacozine-1-carboxamides $(8 a-8 n)$ against the MCF-7, A549 and DU 145 cells $\left(C^{2} C_{50} \text { in } \mu M\right)^{a}$

\begin{tabular}{lrrr}
\hline Compound & MCF7 $(\mu \mathrm{M})$ & A549 $(\mu \mathrm{M})$ & DU145 $(\mu \mathrm{M})$ \\
\hline $\mathbf{8 a}$ & $32.31 \pm 0.99$ & $23.96 \pm 0.99$ & $7.02 \pm 0.54$ \\
$\mathbf{8 b}$ & $25.95 \pm 1.28$ & $19.21 \pm 0.92$ & $12.36 \pm 0.45$ \\
$\mathbf{8 c}$ & $29.23 \pm 0.72$ & $21.03 \pm 1.13$ & $15.25 \pm 0.29$ \\
$\mathbf{8 d}$ & $26.22 \pm 0.52$ & $26.54 \pm 1.14$ & $10.62 \pm 0.77$ \\
$\mathbf{8 e}$ & $28.12 \pm 0.87$ & $17.12 \pm 0.87$ & $15.00 \pm 0.80$ \\
$\mathbf{8 f}$ & $23.18 \pm 1.30$ & $25.09 \pm 1.12$ & $16.32 \pm 0.68$ \\
$\mathbf{8 g}$ & $22.26 \pm 0.95$ & $16.62 \pm 2.09$ & $18.01 \pm 0.32$ \\
$\mathbf{8 h}$ & $32.03 \pm 1.13$ & $21.95 \pm 1.30$ & $16.05 \pm 1.86$ \\
$\mathbf{8 i}$ & $28.36 \pm 0.75$ & $32.23 \pm 0.93$ & $8.95 \pm 0.77$ \\
$\mathbf{8 j}$ & $35.26 \pm 1.27$ & $19.65 \pm 1.16$ & $13.24 \pm 0.60$ \\
$\mathbf{8 k}$ & $27.04 \pm 0.62$ & $25.14 \pm 1.97$ & $18.58 \pm 1.11$ \\
$\mathbf{8 1}$ & $21.05 \pm 0.30$ & $29.08 \pm 2.20$ & $6.32 \pm 0.68$ \\
$\mathbf{8 m}$ & $25.82 \pm 0.90$ & $18.28 \pm 1.58$ & $9.26 \pm 0.57$ \\
$\mathbf{8 n}$ & $23.12 \pm 1.18$ & $24.36 \pm 0.70$ & $19.24 \pm 0.93$ \\
Dermacozine A & $12.26 \pm 0.78$ & $22.36 \pm 1.69$ & $15.62 \pm 2.21$ \\
Nocodazole & $1.23 \pm 0.92$ & $0.96 \pm 0.65$ & $2.62 \pm 1.20$ \\
Paclitaxel & $2.56 \pm 1.53$ & $1.61 \pm 0.93$ & $3.16 \pm 0.93$
\end{tabular}

${ }^{a}$ Values are the mean $\pm \mathrm{SD}, n=3$. 
amide 8a with an electron-donating group (OMe) at the $3^{\text {rd }}$ position showed finer activity as compared to the phenyl amides $\mathbf{8 b}$ and $\mathbf{8 h}$ with electron-withdrawing groups $\left(\mathrm{CF}_{3}\right.$ and $\left.\mathrm{F}\right)$ at the third position, respectively. On the other hand, the aliphatic amide derivatives $\mathbf{8 e}, \mathbf{8 f}, \mathbf{8 g}, \mathbf{8 k}$ and $\mathbf{8 j}$ exhibited moderate anticancer activity against the DU145 cell line. Based on the abovementioned observations, the aryl substituents of dermacozine-1-carboxamides are more favourable to the anticancer activity.

Cell cycle distribution. The results are provided in Table 2 and Fig. 2. The effect of $\mathbf{8 a}$ and $\mathbf{8 1}$ on the cell cycle of the DU145 cells was analyzed by flow cytometry, and the results showed a profound effect of $\mathbf{8 a}$ and $\mathbf{8 1}$ on the cell cycle as these compounds arrested the cell cycle at the G2/M phase; $8 \mathbf{a}$ and $\mathbf{8 1}$ arrested 62.3 and $65.6 \%$ of the cells in the $\mathrm{G} 2 / \mathrm{M}$ phase, respectively, as compared to the case of the control cells (10.2\%).

Effects of $8 \mathrm{a}$ and $8 \mathrm{~g}$ on the expressions of cyclin-B1 and Cdk1. The investigation of the effects of $\mathbf{8 a}$ and $8 \mathbf{1}$ on the expressions of cyclin-B1 and Cdk1 is important as cyclin-B1 and Cdk1 are the key kinases involved in the G2/M phase of cell cycle transition and play an important role in the metaphase by activating the motor proteins required for spindle separation. The activation of Cdk1 primarily involves the expression of cyclin-B1. Hence, in the present study, we studied the expression of Cdk1 and cyclin-B1 after the treatment of the DU 145 cells with the compounds $\mathbf{8 a}, \mathbf{8 1}$ and nocodazole, which acted as a standard. Tubulin acts as a loading control, and the results of the Western blot analysis are shown in Fig. 3. The uniform expression of tubulin in all the lanes indicated uniform sample loading. However, we observed a difference in the expressions of Cdk1 and cyclin-B1 in the treatment groups. The expression of Cdk1 and cyclin-B1 was observed to be comparatively more in the cells treated with the compounds 8a and 81, indicating significant $\mathrm{G} 2 / \mathrm{M}$ arrest by the inhibition of mitosis and interference with spindle separation. Via the Western blot analysis, it was found that 8a and 81 killed the DU 145 cancer cells by inhibiting the cell cycle at mitosis and interfering with spindle separation.

Effect of 8a and 81 on tubulin polymerization. Via the cell cycle analysis, it was evident that $\mathbf{8} \mathbf{a}$ and $\mathbf{8 1}$ arrested the cell cycle at the G2/M phase. These compounds, therefore, might inhibit tubulin polymerization. Hence, we assessed the ability of $\mathbf{8 a}$ and $\mathbf{8 1}$ to inhibit tubulin polymerization. Nocodazole was used as a positive control. 8a and $\mathbf{8 1}$ significantly inhibited tubulin polymerization. They showed potent inhibition of tubulin polymerization with the $\mathrm{IC}_{50}$ values of $2.64 \mu \mathrm{M}$ and $2.36 \mu \mathrm{M}$, respectively, whereas nocodazole showed the $\mathrm{IC}_{50}$ value of $2.51 \mu \mathrm{M}$ (Table 3).

Table 2 Cell cycle distribution of the DU 145 cells at the Sub G1, G0/ G1, S phase and G2/M phase

\begin{tabular}{lllll}
\hline Compound & Sub-G1 & G0/G1 & S phase & G2/M phase \\
\hline Control & 2.8 & 83.3 & 5.6 & 10.2 \\
8a & 1.6 & 24.6 & 8.9 & 62.3 \\
81 & 1.2 & 18.9 & 9.1 & 65.6
\end{tabular}
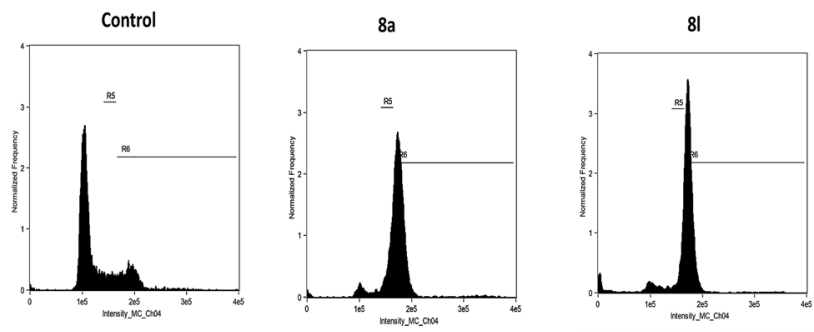

Fig. 2 Cell cycle distribution of the DU145 cells.

Effect of 8a and 81 on the microtubule network. Antimitotic agents affect the microtubule network. We, therefore, observed the alterations in the microtubule network caused by $\mathbf{8 a}$ and $\mathbf{8 1}$ in the DU 145 cells via immune fluorescence microscopy. The test results demonstrated a well-organized microtubular network in the control cells; however, the cells treated with the compounds $\mathbf{8 a}$ and $\mathbf{8 1}$ showed disrupted microtubule organization (Fig. 4), thus demonstrating the inhibition of tubulin polymerization.

\section{Experimental}

\section{Chemistry}

All commercially available reagents used in this study were bought from local suppliers, Sigma-Aldrich and Alfa Aesar, and used as received. Thin-layer chromatography was performed using pre-coated TLC silica gel 60 F254 plates on aluminum (Merck). TLC was visualized via UV-254 at $360 \mathrm{~nm}$ using iodine on silica gel. Column chromatography was performed using 100-200 mesh silica gel. Automated purifications were conducted using the Teledyne ISCO Combiflash companion. Unless otherwise stated, all the reactions were carried out under an atmosphere of argon in dried glassware using standard techniques. The ${ }^{1} \mathrm{H}$ and ${ }^{13} \mathrm{C}$ NMR spectra were obtained using the Varian 400 and Varian 300 spectrometers. Chemical shifts are reported in ppm with TMS as the internal standard. Data are reported as follows: chemical shift, multiplicity ( $\mathrm{s}=$ singlet, $\mathrm{d}=$ doublet, $\mathrm{t}=$ triplet, $\mathrm{q}=$ quartet, $\mathrm{br}=$ broad, $\mathrm{m}=$ multiplet), coupling constants and number of protons. IR spectra were obtained via the FT-IR PerkinElmer Spectrum 2000 using $\mathrm{KBr}$

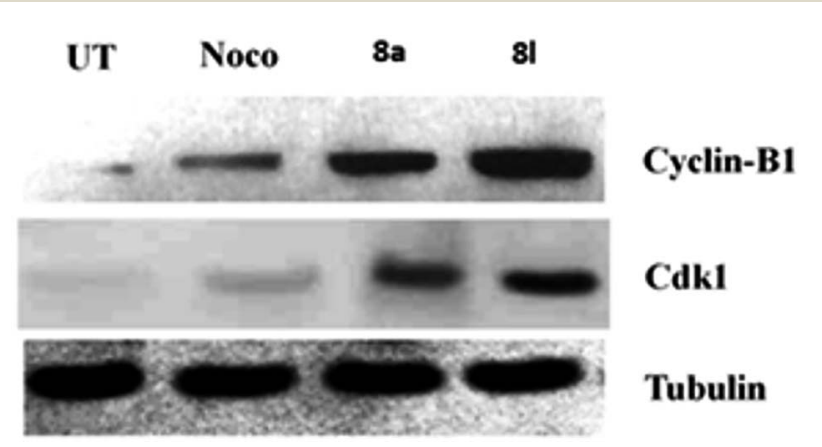

Fig. 3 Immunoblot analysis for the expression of cyclin-B1 and Cdk1. Tubulin was used as a loading control. 
Table 3 Anti-tubulin polymerization inhibitory activity of $8 a$ and 81

\begin{tabular}{ll}
\hline Compound & $\begin{array}{l}\text { Anti-tubulin activity } \\
\left(\mathrm{IC}_{50}, \mu \mathrm{M}\right)\end{array}$ \\
\hline $\mathbf{8 a}$ & 2.64 \\
$\mathbf{8 1}$ & 2.36 \\
Nocodazole & 2.51
\end{tabular}

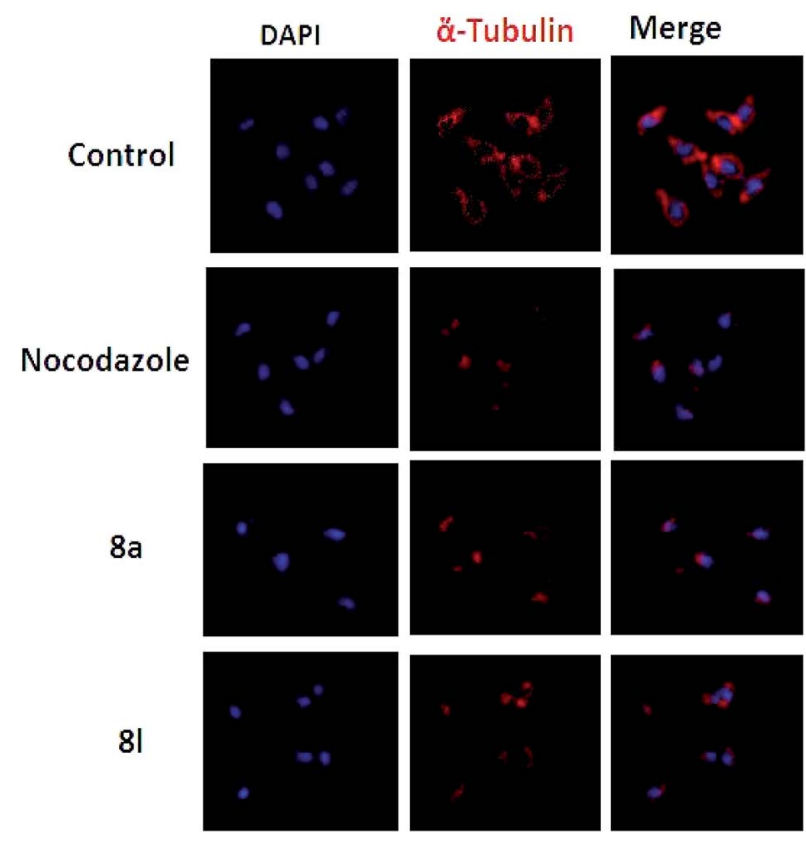

Fig. 4 Effect of $8 \mathrm{a}$ and $8 \mathrm{l}$ on the organization of the cellular microtubule network. $8 \mathrm{a}$ and $8 \mathrm{l}$ altered the tubulin assembly, which showed an irregular morphology. Cells were counterstained with DAPI to stain the nuclei.

pellets. Melting point ( $\mathrm{mp}$ ) determinations were performed using the Mel Temp apparatus, and the values reported herein are uncorrected.

Methyl 2-chloro-3-((2-chloro-6-nitrophenyl)amino)benzoate (3). To a stirred solution of methyl 3-amino-2-chlorobenzoate (1) $(1 \mathrm{~g}, 5.405 \mathrm{mmol})$ in dry $\mathrm{THF}$, cooled to $-78{ }^{\circ} \mathrm{C}, 2 \mathrm{M}$ LiHMDS (5.9 mL, $11.89 \mathrm{mmol})$ in THF $(20 \mathrm{~mL})$ was added followed by stirring at $-78{ }^{\circ} \mathrm{C}$ for $30 \mathrm{~min}$. To this mixture, 1-chloro2-fluoro-3-nitrobenzene (2) (948 $\mathrm{mg}, 5.405 \mathrm{mmol}$ ) dissolved in THF $(10 \mathrm{~mL})$ was added followed by stirring at $-78^{\circ} \mathrm{C}$ for $1 \mathrm{~h}$. After completion of the reaction, the mixture was diluted with a sat. $\mathrm{NH}_{4} \mathrm{Cl}$ solution $(50 \mathrm{~mL})$ and water $(50 \mathrm{~mL})$, extracted with EtOAC $(2 \times 50 \mathrm{~mL})$-combined organic layers, dried over anhydrous sodium sulphate, filtered, and then concentrated under vacuum. The crude product was purified using a 100-200 silica gel column and then eluted with a gradient of $10 \%$ ethyl acetate in pet. ether to afford (1.45 g, 78\%) a light orange solid.

MR: $117-119{ }^{\circ} \mathrm{C} ;{ }^{1} \mathrm{H}$ NMR (400 $\left.\mathrm{MHz}, \mathrm{CDCl}_{3}\right): \delta$ ppm 3.95 $\left(3 \mathrm{H}, \mathrm{s}, \mathrm{COOCH}_{3}\right), 6.67(1 \mathrm{H}, \mathrm{d}, J=8.11 \mathrm{~Hz}, \mathrm{Ar}-\mathrm{H}), 7.08-7.29(2 \mathrm{H}$, $\mathrm{m}, \mathrm{Ar}-\mathrm{H}), 7.39(1 \mathrm{H}, \mathrm{dd}, J=7.67,1.10 \mathrm{~Hz}, \mathrm{Ar}-\mathrm{H}), 7.69(1 \mathrm{H}, \mathrm{dd}, J=$ 7.89, $1.10 \mathrm{~Hz}, \mathrm{Ar}-\mathrm{H}), 8.02$ (1H, dd, $J=8.33,1.32 \mathrm{~Hz}, \mathrm{Ar}-\mathrm{H}), 8.09$ $(1 \mathrm{H}, \mathrm{s}, \mathrm{NH}) ;{ }^{13} \mathrm{C} \mathrm{NMR}\left(101 \mathrm{MHz}, \mathrm{CDCl}_{3}\right): \delta \mathrm{ppm} 52.4\left(\mathrm{OCH}_{3}\right)$,
$119.7,122.2$, 123.6, 123.8, 124.7, 126.2, 130.5, 131.4, 134.2, 136.0, 139.3, 143.9 (Ar-C), 166.2 (COOMe); LCMS (ES): $\mathrm{m} / \mathrm{z}$ $338.98(\mathrm{M}-\mathrm{H})^{+}$; FT-IR (KBr) $\nu_{\max } 3363(\mathrm{NH}), 3098,1721(\mathrm{C}=\mathrm{O})$, 1577, 1492, 1339, 1280 (Ar-Cl), $746 \mathrm{~cm}^{-1}$.

Methyl 2-chloro-3-((2-chloro-6-nitrophenyl)(methyl)amino) benzoate (4). To a stirred solution of methyl 2-chloro-3-((2chloro-6-nitrophenyl)amino)benzoate (3) (1.4 g, $4.10 \mathrm{mmol})$ in DMF $(30 \mathrm{~mL}), \mathrm{KOH}$ pellets $(919 \mathrm{mg}, 16.42 \mathrm{mmol})$ were added followed by stirring at room temperature for $1 \mathrm{~h}$. To this, methyl iodide (1.15 g, $8.2 \mathrm{mmol}$ ) was added followed by stirring at room temperature for $16 \mathrm{~h}$. The reaction mixture was poured in ice water $(100 \mathrm{~mL})$, and a solid was formed, which was filtered under vacuum and dried to afford (1.35 g, 90\%) a light yellow solid.

MR: $122-124{ }^{\circ} \mathrm{C} ;{ }^{1} \mathrm{H}$ NMR (400 $\left.\mathrm{MHz}, \mathrm{CDCl}_{3}\right): \delta$ ppm 3.38 $\left(3 \mathrm{H}, \mathrm{s}, \mathrm{N}-\mathrm{CH}_{3}\right), 3.85\left(3 \mathrm{H}, \mathrm{s}, \mathrm{COOCH}_{3}\right), 7.20-7.36(4 \mathrm{H}, \mathrm{m}, \mathrm{Ar}-\mathrm{H})$, $7.56(1 \mathrm{H}, \mathrm{dd}, J=8.11,1.32 \mathrm{~Hz}, \mathrm{Ar}-\mathrm{H}), 7.66(1 \mathrm{H}, \mathrm{dd}, J=8.00$, $1.43 \mathrm{~Hz}, \mathrm{Ar}-\mathrm{H}) ;{ }^{13} \mathrm{C}$ NMR (101 MHz, $\left.\mathrm{CDCl}_{3}\right): \delta \mathrm{ppm} 41.0(\mathrm{~N}-$ $\left.\mathrm{CH}_{3}\right), 52.3\left(\mathrm{COOCH}_{3}\right), 123.5,124.1,124.4,124.5,126.0,126.7$, 133.1, 134.6, 135.8, 139.7, 145.0, $149.0(\mathrm{Ar}-\mathrm{H}), 166.6\left(\mathrm{COOCH}_{3}\right)$; LCMS (ES): $m / z 355.07(\mathrm{M}+\mathrm{H})^{+}$; FT-IR (KBr) $\nu_{\max } 3433(\mathrm{NH})$, 2954, 1727 (C=O), 1437, 1276.9 (Ar-Cl), 1046, $766 \mathrm{~cm}^{-1}$.

Methyl 3-((2-amino-6-chlorophenyl)(methyl)amino)-2chlorobenzoate (5). To a stirred solution of methyl 2-chloro-3((2-chloro-6-nitrophenyl)(methyl)amino)benzoate (4) (1.3 g, $3.66 \mathrm{mmol})$ in DMF (20 mL), Fe powder (1.0 g, $18.3 \mathrm{mmol})$ was added followed by $\mathrm{NH}_{4} \mathrm{Cl}(970 \mathrm{mg}, 18.3 \mathrm{mmol})$, and then, the reaction mixture was heated to $90{ }^{\circ} \mathrm{C}$ for $5 \mathrm{~h}$. The reaction mixture was then cooled down to room temperature, diluted with EtOAC $(80 \mathrm{~mL})$, passed through a Celite bed and washed with EtOAC $(10 \mathrm{~mL})$. The filtrate was washed with water $(3 \times 100$ $\mathrm{mL})$ and brine $(100 \mathrm{~mL})$, dried over anhydrous sodium sulphate and concentrated under reduced pressure. The crude material was purified by silica gel column chromatography using a 10$15 \%$ gradient of EtOAC in petroleum ether to afford $5(800 \mathrm{mg}$, $67 \%$ ) as an off-white solid and the cyclized compound 6 (100 mg, 10\%) as a fluorescent yellow solid.

MR: $122-124{ }^{\circ} \mathrm{C} ;{ }^{1} \mathrm{H}$ NMR (400 $\left.\mathrm{MHz}, \mathrm{CDCl}_{3}\right): \delta$ ppm 3.24 $\left(3 \mathrm{H}, \mathrm{s}, \mathrm{N}-\mathrm{CH}_{3}\right), 3.87\left(3 \mathrm{H}, \mathrm{s}, \mathrm{COOCH}_{3}\right), 4.18\left(2 \mathrm{H}, \mathrm{br} \mathrm{s}, \mathrm{Ar}-\mathrm{NH}_{2}\right)$, $6.67(2 \mathrm{H}, \mathrm{m}, \mathrm{Ar}-\mathrm{H}), 6.92-6.98(1 \mathrm{H}, \mathrm{dd}, J=12.72,8.11,1.10 \mathrm{~Hz}$, $\mathrm{Ar}-\mathrm{H}), 7.23-7.31$ (3H, m, Ar-H); ${ }^{13} \mathrm{C}$ NMR (101 MHz, $\mathrm{CDCl}_{3}$ ): $\delta$ ppm $39.5\left(\mathrm{~N}-\mathrm{CH}_{3}\right), 52.3\left(\mathrm{COOCH}_{3}\right), 114.1,119.7,122.6,123.0$ (2C), 126.7, 127.8, 131.0, 133.2, 133.5, 146.0, 147.8 (Ar-C), 167.2 $\left(\mathrm{COOCH}_{3}\right)$; LCMS (ES): $m / z 325.08(\mathrm{M})^{+}$; FT-IR (KBr) $\nu_{\max } 3447$ $(\mathrm{NH}), 3358\left(\mathrm{NH}_{2}\right), 2899,1720\left(\mathrm{COOCH}_{3}\right), 1257$ (Ar-Cl), 1047, $758 \mathrm{~cm}^{-1}$.

Methyl 6-chloro-5-methyl-5,10-dihydrophenazine-1carboxylate (6). An argon-purged reaction tube was charged with Johnphos (485 mg, $1.63 \mathrm{mmol}$ ), $\mathrm{Pd}_{2}(\mathrm{dba})_{3}$ (745 mg, 0.815 $\mathrm{mmol})$, and dry toluene $(25 \mathrm{~mL})$ and purged with argon for $10 \mathrm{~min}$. To this, methyl 3-((2-amino-6-chlorophenyl)(methyl) amino)-2-chlorobenzoate (5) (2.65 g, $8.15 \mathrm{mmol}$ ) and $\mathrm{Cs}_{2} \mathrm{CO}_{3}$ $(5.31 \mathrm{~g}, 16.3 \mathrm{mmol})$ were added under an inert atmosphere. The reaction mixture was heated to $120{ }^{\circ} \mathrm{C}$ and stirred at the same temperature in a sealed tube for $40 \mathrm{~h}$. The reaction mixture was then cooled down to room temperature, diluted with EtOAC $(100 \mathrm{~mL})$, passed through a Celite bed and washed again with 
EtOAC $(10 \mathrm{~mL})$. The filtrate was concentrated under reduced pressure, and the obtained residue was purified by methanol $(20 \mathrm{~mL})$ washing, filtered and dried to afford $6(2.1 \mathrm{~g}, 79 \%)$ as a florescent yellow solid.

MR: $72-74{ }^{\circ} \mathrm{C} ;{ }^{1} \mathrm{H}$ NMR (400 MHz, DMSO-d 6 ): $\delta$ ppm 3.24 $\left(3 \mathrm{H}, \mathrm{s}, \mathrm{N}-\mathrm{CH}_{3}\right), 3.83\left(3 \mathrm{H}, \mathrm{s}, \mathrm{COOCH}_{3}\right), 6.60-6.87$ (5H, m, Ar-H), $7.27(1 \mathrm{H}$, br d, $J=7.89 \mathrm{~Hz}, \mathrm{Ar}-\mathrm{H}), 9.09(1 \mathrm{H}, \mathrm{s}, \mathrm{NH}) ;{ }^{13} \mathrm{C} \mathrm{NMR}$ $\left(101 \mathrm{MHz}, \mathrm{DMSO}-\mathrm{d}_{6}\right) \delta$ ppm $45.2\left(\mathrm{~N}-\mathrm{CH}_{3}\right), 52.3\left(\mathrm{COOCH}_{3}\right)$, $109.8,113.1,113.3,120.3,122.8,124.0,124.3,124.8,132.7$, 138.7, 139.2, 141.7 (Ar-C), $167.8\left(\mathrm{COOCH}_{3}\right)$; LCMS (ES): $\mathrm{m} / \mathrm{z}$ $288.23(\mathrm{M})^{+}$.

6-Chloro-5-methyl-5,10-dihydrophenazine-1-carboxylic acid (7). To a stirred solution of methyl 6-chloro-5-methyl-5,10dihydrophenazine-1-carboxylate (6) $(500 \mathrm{mg}, 1.73 \mathrm{mmol})$ in ethanol-THF $(2: 1 ; 15 \mathrm{~mL}), 4 \mathrm{~N}$ aqueous $\mathrm{NaOH}$ solution (173 $\mathrm{mg}, 4.34 \mathrm{mmol}$ ) was added followed by stirring at room temperature for $5 \mathrm{~h}$. The reaction mixture was concentrated under vacuum, diluted with water $(20 \mathrm{~mL})$, and adjusted to $\mathrm{pH}$ $\sim 5$ with a $4 \mathrm{~N}$ aqueous $\mathrm{HCl}$ solution $(2 \mathrm{~mL})$ to obtain a solid, which was filtered and dried. Again the crude was triturated with pentane $(15 \mathrm{~mL})$ decant and dried to afford the acid 7 (350 $\mathrm{mg}, 73 \%$ ) as a yellowish brown solid.

MR: $210-212{ }^{\circ} \mathrm{C} ;{ }^{1} \mathrm{H}$ NMR (400 MHz, DMSO-d ${ }_{6}$ ): $\delta$ ppm 3.24 $\left(3 \mathrm{H}, \mathrm{s}, \mathrm{N}-\mathrm{CH}_{3}\right), 6.54-6.88(5 \mathrm{H}, \mathrm{m}, \mathrm{Ar}-\mathrm{H}), 7.28(1 \mathrm{H}, \mathrm{dd}, J=8.11$, $1.32 \mathrm{~Hz}, \mathrm{Ar}-\mathrm{H}), 9.32$ (1H, s, Ar-NH), 13.08 (1H, br s, COOH); ${ }^{13} \mathrm{C}$ NMR (101 MHz, DMSO-d 6 ): $\delta$ ppm $45.8\left(\mathrm{~N}-\mathrm{CH}_{3}\right), 110.7,113.0$, 122.5, 122.9, 122.9, 123.8, 124.8 (2C), 132.7, 138.6, 139.4, 141.9 (Ar-C), 169.5 (COOH); LCMS (ES): $m / z 274.07(\mathrm{M})^{+}$.

General procedure for amide coupling. To a stirred solution of 6-chloro-5-methyl-5,10-dihydro phenazine-1-carboxylic acid 7 (70 $\mathrm{mg}, 0.25 \mathrm{mmol}$ ) in DMF $(15 \mathrm{~mL})$, amines (0.379 mmol), HATU (292 mg, $0.5 \mathrm{mmol}$ ) and diisopropylethylamine (0.75 $\mathrm{mmol}$ ) were added at room temperature followed by stirring for $1 \mathrm{~h}$. The reaction mixture was diluted with EtOAC $(80 \mathrm{~mL})$ and washed with cold water $(2 \times 50 \mathrm{~mL})$ and brine $(50 \mathrm{~mL})$; then, the organic layer was dried over anhydrous sodium sulphate and concentrated under reduced pressure. The crude material was purified by silica gel column chromatography using a $10-40 \%$ gradient of EtOAC in petroleum ether to afford the required compound in a yield of $60-90 \%$.

6-Chloro- $\mathrm{N}$-(3-methoxyphenyl)-5-methyl-5,10-dihydrophenazine1-carboxamide (8a). Appearance: greenish yellow solid; yield: 69\%; MR: $147-149{ }^{\circ} \mathrm{C} ;{ }^{1} \mathrm{H}$ NMR (400 MHz, DMSO-d $\left.\mathrm{d}_{6}\right): \delta \mathrm{ppm}$ $3.25\left(3 \mathrm{H}, \mathrm{s}, \mathrm{N}-\mathrm{CH}_{3}\right), 3.76\left(3 \mathrm{H}, \mathrm{s}, \mathrm{O}-\mathrm{CH}_{3}\right), 6.61(1 \mathrm{H}, \mathrm{dd}, J=7.13$, $1.86 \mathrm{~Hz}, \mathrm{Ar}-\mathrm{H}), 6.66-6.84(5 \mathrm{H}, \mathrm{m}, \mathrm{Ar}-\mathrm{H}), 7.21-7.33(3 \mathrm{H}, \mathrm{m}, \mathrm{Ar}-$ H), 7.36-7.39 (1H, m, Ar-H), $9.21(1 \mathrm{H}, \mathrm{s}, \mathrm{NH}), 10.12(1 \mathrm{H}, \mathrm{s}$, $\mathrm{CONH}) ;{ }^{13} \mathrm{C}$ NMR (101 MHz, DMSO-d 6 ): $\delta$ ppm $45.3\left(\mathrm{~N}-\mathrm{CH}_{3}\right)$, $55.0\left(\mathrm{OCH}_{3}\right), 106.7,109.3,112.4,113.1,114.9,119.6,121.0$, 122.3, 122.5, 122.8, 124.3, 129.2, 132.2, 138.3, 139.6 (2C), 139.7 (Ar-C), $159.3\left(\mathrm{Ar}-\mathrm{C}-\mathrm{OCH}_{3}\right), 166.6(\mathrm{CONH}) ; \mathrm{LCMS}$ (ES): $\mathrm{m} / \mathrm{z}$ $379.12(\mathrm{M})^{+}$; FT-IR (KBr) $\nu_{\max } 3356(\mathrm{NH}), 3240(\mathrm{CONH}), 2928$, $1638(\mathrm{C}=\mathrm{O}), 1481,1273(\mathrm{Ar}-\mathrm{Cl}), 717 \mathrm{~cm}^{-1}$.

6-Chloro-5-methyl- $\mathrm{N}$-(3-(trifluoromethyl)phenyl)-5,10-dihydrophenazine-1-carboxamide (8b). Appearance: light green solid; yield: 72\%; MR: $187-189{ }^{\circ} \mathrm{C}$; ${ }^{1} \mathrm{H}$ NMR (400 MHz, DMSO-d 6 ): $\delta$ ppm 3.25 (3H, s, $\left.\mathrm{NCH}_{3}\right)$ 6.61-6.67 (1H, m, Ar-H), 6.69-6.87 (4H, $\mathrm{m}, \mathrm{Ar}-\mathrm{H}), 7.32(1 \mathrm{H}, \mathrm{d}, J=7.89 \mathrm{~Hz}, \mathrm{Ar}-\mathrm{H}), 7.46(1 \mathrm{H}, \mathrm{br} \mathrm{d}, J=$
$7.67 \mathrm{~Hz}, \mathrm{Ar}-\mathrm{H}) 7.60(1 \mathrm{H}, \mathrm{t}, J=8.00 \mathrm{~Hz}, \mathrm{Ar}-\mathrm{H}) 7.96(1 \mathrm{H}, \mathrm{br} \mathrm{d}, J=$ $8.11 \mathrm{~Hz}, \mathrm{Ar}-\mathrm{H}) 8.20$ (1H, s, ArH) $9.14(1 \mathrm{H}, \mathrm{s}, \mathrm{NH}) 10.44(1 \mathrm{H}, \mathrm{s}$, $\mathrm{CONH}) ;{ }^{13} \mathrm{C}$ NMR (101 MHz, DMSO-d 6 ): $\delta$ ppm $45.3\left(\mathrm{~N}-\mathrm{CH}_{3}\right)$, 112.6, 114.5, 116.8, 116.9, 119.7, 120.0, 121.2, 122.3, 122.4, 122.7, 124.3, 125.4, 129.0, 129.3, 129.6, 132.2, 138.3, 139.4, 139.6 (Ar-C), 166.9 (CONH); LCMS (ES): $m / z$ 417.21 (M) ${ }^{+}$; FT-IR (KBr) $\nu_{\text {max }}: 3361$ $(\mathrm{NH}), 3282(\mathrm{CONH}), 2923,1635(\mathrm{C}=\mathrm{O}), 1447,1249$ (Ar-Cl), $768 \mathrm{~cm}^{-1}$.

6-Chloro- $N$-(4-fluoro-1H-pyrazol-5-yl)-5-methyl-5,10-dihydrophenazine-1-carboxamide (8c). Appearance: light orange solid; yield: 69\%; MR: 229-231 ${ }^{\circ} \mathrm{C}$; ${ }^{1} \mathrm{H}$ NMR (400 MHz, DMSO-d 6 ): $\delta$ ppm $3.24\left(3 \mathrm{H}, \mathrm{s}, \mathrm{N}-\mathrm{CH}_{3}\right), 5.97(2 \mathrm{H}, \mathrm{s}, \mathrm{Ar}-\mathrm{H}), 6.55-6.82(5 \mathrm{H}, \mathrm{m}$, $\mathrm{Ar}-\mathrm{H}), 7.08$ (1H, dd, $J=8.00,1.43 \mathrm{~Hz}, \mathrm{Ar}-\mathrm{H}), 8.14(1 \mathrm{H}, \mathrm{s}, \mathrm{CONH})$, $8.28(1 \mathrm{H}, \mathrm{s}, \mathrm{NH}) ;{ }^{13} \mathrm{C}$ NMR (101 MHz, DMSO-d 6 ): $\delta \mathrm{ppm} 45.3(\mathrm{~N}-$ $\left.\mathrm{CH}_{3}\right), 112.5,114.8,115.3,119.2,120.9,122.7,124.2,125.2$, 132.3, 137.8, 138.4, 139.9, 141.2, 143.8, 148.6 (Ar-C), 164.4 (CONH); LCMS (ES): $m / z 358.16(\mathrm{M}+\mathrm{H})^{+}$; FT-IR (KBr) $\nu_{\max } 3410$ (NH), 2919, 1665 (CONH), 1378, 1277 (Ar-Cl), $744 \mathrm{~cm}^{-1}$.

6-Chloro-5-methyl- $N$-(3,4,5-trimethoxyphenyl)-5,10-dihydrophenazine-1-carboxamide (8d). Appearance: light yellow solid; yield: 75\%; MR: $235-237{ }^{\circ} \mathrm{C}$; ${ }^{1} \mathrm{H}$ NMR (400 MHz, DMSO-d 6 ): $\delta$ ppm $3.25\left(3 \mathrm{H}, \mathrm{s}, \mathrm{N}-\mathrm{CH}_{3}\right), 3.65\left(3 \mathrm{H}, \mathrm{s}, \mathrm{OCH}_{3}\right), 3.77(6 \mathrm{H}, \mathrm{s}$, $\left.\mathrm{OCH}_{3}\right), 6.61(1 \mathrm{H}, \mathrm{dd}, J=7.13,1.86 \mathrm{~Hz}, \mathrm{Ar}-\mathrm{H}), 6.66-6.88(4 \mathrm{H}, \mathrm{m}$, $\mathrm{Ar}-\mathrm{H}), 7.13(2 \mathrm{H}, \mathrm{s}, \mathrm{Ar}-\mathrm{H}) \mathrm{7}$ 7.22-7.35 (1H, m, Ar-H), $9.22(1 \mathrm{H}, \mathrm{s}$, $\mathrm{NH}), 10.04(1 \mathrm{H}, \mathrm{s}, \mathrm{CONH}) ;{ }^{13} \mathrm{C}$ NMR (101 MHz, DMSO-d 6 ): $\delta$ ppm $45.2\left(\mathrm{~N}-\mathrm{CH}_{3}\right), 55.7\left(2 \mathrm{C}, \mathrm{OCH}_{3}\right), 60.7\left(\mathrm{OCH}_{3}\right), 98.8,112.4$, 114.9, 119.6, 121.0, 122.2, 122.5 (2C), 122.8, 124.3, 132.2, 134.0, 134.6, 138.3, 139.5 (Ar-C), $139.7\left(\mathrm{Ar}-\mathrm{C}-\mathrm{OCH}_{3}\right), 152.5$ (2C, $\mathrm{Ar}-\mathrm{C}-$ $\left.\mathrm{OCH}_{3}\right), 166.4$ (CONH); LCMS (ES): $m / z 440.21(\mathrm{M}+\mathrm{H})^{+}$; FT-IR $(\mathrm{KBr}) \nu_{\max } 3392(\mathrm{NH}), 2938,1641(\mathrm{CONH}), 1449,1231$ (Ar-Cl), $763 \mathrm{~cm}^{-1}$; HR-MS (ESI): $m / z$ calcd for $\mathrm{C}_{23} \mathrm{H}_{22} \mathrm{ClN}_{3} \mathrm{O}_{4}\left([\mathrm{M}+\mathrm{H}]^{+}\right)$: 440.1377 found: 440.1372 .

6-Chloro- $N$-cycloheptyl-5-methyl-5,10-dihydrophenazine-1carboxamide (8e). Appearance: light green solid; yield: 89\%; MR: $216-218{ }^{\circ} \mathrm{C} ;{ }^{1} \mathrm{H}$ NMR (400 MHz, DMSO-d ${ }_{6}$ ): $\delta$ ppm 1.35-1.71 (10H, m, $\left.\mathrm{CH}_{2}\right), 1.78-1.87\left(2 \mathrm{H}, \mathrm{m}, \mathrm{CH}_{2}\right), 3.21\left(3 \mathrm{H}, \mathrm{s}, \mathrm{N}-\mathrm{CH}_{3}\right)$, 3.90-3.99 (1H, m, CONH-CH), $6.53(1 \mathrm{H}, \mathrm{dd}, J=6.25,2.96 \mathrm{~Hz}$, $\mathrm{Ar}-\mathrm{H}), 6.64-6.79(4 \mathrm{H}, \mathrm{m}, \mathrm{Ar}-\mathrm{H}), 7.20(1 \mathrm{H}, \mathrm{d}, J=7.67 \mathrm{~Hz}, \mathrm{Ar}-\mathrm{H})$, 8.18-8.24 (1H, m, CONH), $9.73(1 \mathrm{H}, \mathrm{s}, \mathrm{NH}) ;{ }^{13} \mathrm{C}$ NMR (101 MHz, DMSO-d 6 ): $\delta$ ppm $23.9\left(2 \mathrm{C}, \mathrm{CH}_{2}\right) 27.6\left(2 \mathrm{C}, \mathrm{CH}_{2}\right) 34.1\left(2 \mathrm{C}, \mathrm{CH}_{2}\right)$ $45.2\left(\mathrm{NCH}_{3}\right) 50.2(\mathrm{CONH}-\mathrm{CH})$ 112.2, 114.2, 119.4, 120.7, 121.9, 122.4, 122.6, 124.4, 132.1, 138.1, 139.7, 139.8 (Ar-C), 166.5 (CONH); LCMS (ES): $m / z 370.39(\mathrm{M}+\mathrm{H})^{+}$; FT-IR (KBr) $\nu_{\max } 3406$ $(\mathrm{NH}), 2936,1630(\mathrm{C}=\mathrm{O}), 1474,1276(\mathrm{Ar}-\mathrm{Cl}), 741 \mathrm{~cm}^{-1}$.

6-Chloro-5-methyl- $N$-phenethyl-5,10-dihydrophenazine-1carboxamide (8f). Appearance: yellowish green solid; yield: 76\%; MR: $147-149{ }^{\circ} \mathrm{C} ;{ }^{1} \mathrm{H}$ NMR (400 MHz, DMSO-d 6 ): $\delta$ ppm $2.84\left(2 \mathrm{H}\right.$, br t, $\left.J=7.34 \mathrm{~Hz}, \mathrm{Ar}-\mathrm{CH}_{2}\right), 3.22\left(3 \mathrm{H}, \mathrm{s}, \mathrm{NCH}_{3}\right), 3.42-$ $3.51\left(2 \mathrm{H}, \mathrm{m}, \mathrm{CONH}-\mathrm{CH}_{2}\right), 6.52(1 \mathrm{H}, \mathrm{dd}, J=6.36,2.85 \mathrm{~Hz}, \mathrm{Ar}-\mathrm{H})$, 6.65-6.78 (4H, m, Ar-H), 7.13 (1H, br d, J= 7.23 Hz, Ar-H), 7.18$7.33(5 \mathrm{H}, \mathrm{m}, \mathrm{Ar}-\mathrm{H}), 8.55$ (1H, br s, CONH), $9.74(1 \mathrm{H}, \mathrm{s}, \mathrm{NH}) ;{ }^{13} \mathrm{C}$ NMR (101 MHz, DMSO-d $\left.{ }_{6}\right): \delta$ ppm $34.9\left(\mathrm{Ar}-\mathrm{CH}_{2}\right), 40.5(\mathrm{CONH}-$ $\left.\mathrm{CH}_{2}\right), 45.2\left(\mathrm{~N}-\mathrm{CH}_{3}\right), 112.2,113.8,119.6,120.6,121.5,122.5$, 122.7, 124.4, 126.0, 128.2, 128.3, 128.5, 128.9, 132.1, 133.6, 138.3, 139.3, 139.8 (Ar-C), 167.7 (CONH); LCMS (ES): $m / z 378.20$ $(\mathrm{M}+\mathrm{H})^{+}$; FT-IR $(\mathrm{KBr}) \nu_{\max } 3373(\mathrm{NH}), 2924,1629(\mathrm{C}=\mathrm{O}), 1459$, 
$1274(\mathrm{Ar}-\mathrm{Cl}), 740 \mathrm{~cm}^{-1}$; HR-MS (ESI): $\mathrm{m} / z$ calcd for $\mathrm{C}_{22} \mathrm{H}_{21} \mathrm{ClN}_{3} \mathrm{O}$ $\left([\mathrm{M}+\mathrm{H}]^{+}\right): 378.1373$ found: 378.1367 .

6-Chloro- $\mathrm{N}$-(2-hydroxyethyl)-5-methyl-5,10-dihydro phenazine-1carboxamide (8g). Appearance: yellowish green solid; yield: 69\%; MR: $143-145{ }^{\circ} \mathrm{C} ;{ }^{1} \mathrm{H}$ NMR (400 MHz, DMSO-d $\left.\mathrm{d}_{6}\right): \delta \mathrm{ppm}$ $3.22\left(3 \mathrm{H}, \mathrm{s}, \mathrm{N}-\mathrm{CH}_{3}\right), 3.26-3.36\left(2 \mathrm{H}, \mathrm{m}, \mathrm{CONH}-\mathrm{CH}_{2}\right), 3.51(2 \mathrm{H}, \mathrm{q}$, $\left.J=5.99 \mathrm{~Hz}, \mathrm{O}-\mathrm{CH}_{2}\right), 4.70(1 \mathrm{H}, \mathrm{t}, J=5.59 \mathrm{~Hz}, \mathrm{OH}), 6.51(1 \mathrm{H}, \mathrm{dd}, J$ $=6.36,2.63 \mathrm{~Hz}, \mathrm{Ar}-\mathrm{H}), 6.62-6.81(4 \mathrm{H}, \mathrm{m}, \mathrm{Ar}-\mathrm{H}), 7.19(1 \mathrm{H}, \mathrm{d}, J=$ $7.67 \mathrm{~Hz}, \mathrm{Ar}-\mathrm{H}), 8.40(1 \mathrm{H}, \mathrm{br} \mathrm{t}, J=4.93 \mathrm{~Hz}, \mathrm{CONH}), 9.77(1 \mathrm{H}, \mathrm{s}$, $\mathrm{NH}) ;{ }^{13} \mathrm{C}$ NMR (101 MHz, DMSO-d $\left.{ }_{6}\right): \delta$ ppm $41.8\left(\mathrm{CONH}-\mathrm{CH}_{2}\right)$, $45.2\left(\mathrm{~N}-\mathrm{CH}_{3}\right), 59.4\left(\mathrm{CH}_{2}-\mathrm{OH}\right), 112.1,113.9,119.5,120.6,121.6$, 122.5, 122.7, 124.4, 132.1, 138.2, 139.7, 139.7 (Ar-C), 167.8 (CONH); LCMS (ES): $m / z 318.13(\mathrm{M}+\mathrm{H})^{+}$; FT-IR (KBr) $\nu_{\max } 3330$ (NH), 2922, 1622 (CONH), 1487, 1450, 1278 (Ar-Cl), $756 \mathrm{~cm}^{-1}$; HR-MS (ESI): $m / z$ calcd for $\mathrm{C}_{16} \mathrm{H}_{16} \mathrm{ClN}_{3} \mathrm{O}_{2}\left([\mathrm{M}+\mathrm{H}]^{+}\right): 318.1009$ found: 318.1005.

6-Chloro- $\mathrm{N}$-(3-fluorophenyl)-5-methyl-5,10-dihydrophenazine-1carboxamide (8h). Appearance: yellowish green solid; yield: 77\%; MR: $143-145{ }^{\circ} \mathrm{C} ;{ }^{1} \mathrm{H}$ NMR (400 MHz, DMSO-d 6 ): $\delta \mathrm{ppm}$ $3.25\left(3 \mathrm{H}, \mathrm{s}, \mathrm{N}-\mathrm{CH}_{3}\right), 6.62(1 \mathrm{H}, \mathrm{dd}, J=7.23,1.75 \mathrm{~Hz}, \mathrm{Ar}-\mathrm{H}), 6.69-$ $6.87(3 \mathrm{H}, \mathrm{m}, \mathrm{Ar}-\mathrm{H}), 6.94(1 \mathrm{H}, \mathrm{td}, J=8.39,2.30 \mathrm{~Hz}, \mathrm{Ar}-\mathrm{H}), 7.20-$ $7.43(1 \mathrm{H}, \mathrm{m}, \mathrm{Ar}-\mathrm{H}), 7.27-7.31(1 \mathrm{H}, \mathrm{m}, \mathrm{Ar}-\mathrm{H}), 7.34-7.43(1 \mathrm{H}, \mathrm{m}$, $\mathrm{Ar}-\mathrm{H}), 7.50(1 \mathrm{H}, \mathrm{d}, J=8.33 \mathrm{~Hz}, \mathrm{Ar}-\mathrm{H}), 7.69(1 \mathrm{H}, \mathrm{dt}, J=11.73$, $2.14 \mathrm{~Hz}, \mathrm{Ar}-\mathrm{H}), 9.14$ (1H, s, NH) 10.32 (1H, s, CONH); ${ }^{13} \mathrm{C}$ NMR (101 MHz, DMSO-d $\left.\mathrm{d}_{6}\right): \delta$ ppm $45.3\left(\mathrm{NCH}_{3}\right), 107.6,110.1,110.3$, $112.5,114.7,116.5,119.7,121.2,122.3,122.5,122.9,124.4$, 130.0, 130.1, 132.2, 138.3, 139.6, 140.4 (Ar-C), 166.8 (CONH); LCMS (ES): $m / z 367.22(\mathrm{M})^{+}$; FT-IR (KBr) $\nu_{\max } 3303(\mathrm{NH}), 2920$, 1634 (CONH), 1604, 1486, 1275 (Ar-Cl), $716 \mathrm{~cm}^{-1}$.

6-Chloro-5-methyl- $N$-phenyl-5,10-dihydrophenazine-1-carboxamide (8i). Appearance: light yellow solid; yield: 78\%; MR: 196$198{ }^{\circ} \mathrm{C} ;{ }^{1} \mathrm{H}$ NMR (400 MHz, DMSO-d 6 ): $\delta$ ppm $3.25(3 \mathrm{H}, \mathrm{s}, \mathrm{N}-$ $\left.\mathrm{CH}_{3}\right), 6.60(1 \mathrm{H}, \mathrm{dd}, J=7.23,1.97 \mathrm{~Hz}, \mathrm{Ar}-\mathrm{H}), 6.68-6.86(4 \mathrm{H}, \mathrm{m}, \mathrm{Ar}-$ $\mathrm{H})$, 7.07-7.15 (1H, m, Ar-H), 7.26-7.41 (3H, m, Ar-H), 7.65-7.75 $(2 \mathrm{H}, \mathrm{m}, \mathrm{Ar}-\mathrm{H}), 9.25(1 \mathrm{H}, \mathrm{s}, \mathrm{NH}), 10.16(1 \mathrm{H}, \mathrm{s}, \mathrm{CONH}) ;{ }^{13} \mathrm{C} \mathrm{NMR}$ (101 MHz, DMSO-d $\left.{ }_{6}\right): \delta$ ppm $45.3\left(\mathrm{NCH}_{3}\right), 112.4,114.8,119.7$, 120.9, 121.1, 122.3, 122.5, 122.8, 123.8, 124.4, 128.4 (3C), 132.2, 138.3, 138.5, 139.6, 139.7 (Ar-C), 166.6 (CONH); LCMS (ES): $m / z$ $350.05(\mathrm{M}+\mathrm{H})^{+}$; FT-IR $(\mathrm{KBr}) \nu_{\max } 3338(\mathrm{NH}), 3050,1631(\mathrm{CONH})$, 1480, 1270 (Ar-Cl), $760 \mathrm{~cm}^{-1}$; HR-MS (ESI): $\mathrm{m} / z$ calcd for $\mathrm{C}_{20} \mathrm{H}_{16} \mathrm{ClN}_{3} \mathrm{O}\left([\mathrm{M}-\mathrm{H}]^{+}\right)$: 348.0904 found: 348.0914 .

(6-Chloro-5-methyl-5,10-dihydrophenazin-1-yl)(piperidin-1yl)methanone (8j). Appearance: light green gummy; yield: $84 \%$; ${ }^{1} \mathrm{H}$ NMR (400 MHz, DMSO-d ${ }_{6}$ ): $\delta$ ppm 1.43-1.67 $\left(6 \mathrm{H}, \mathrm{m}, \mathrm{CH}_{2}\right)$, $3.21\left(3 \mathrm{H}, \mathrm{s}, \mathrm{N}-\mathrm{CH}_{3}\right) 3.32-3.61\left(4 \mathrm{H}, \mathrm{m}, \mathrm{N}-\mathrm{CH}_{2}\right), 6.59(1 \mathrm{H}, \mathrm{dd}, J=$ 5.92, 3.07 Hz, Ar-H), 6.66-6.75 (5H, m, Ar-H), 7.59 (1H, s, NH); ${ }^{13} \mathrm{C}$ NMR (101 MHz, DMSO-d $\left.{ }_{6}\right): \delta$ ppm $23.9\left(\mathrm{CH}_{2}\right), 25.3(2 \mathrm{C}$, $\mathrm{CH}_{2}$ ), 28.9 (2C, $\left.\mathrm{CONH}-\mathrm{CH}_{2}\right), 45.2\left(\mathrm{NCH}_{3}\right), 112.2,119.1,119.7$, 120.4, 121.4, 122.2, 122.6, 124.2, 132.2, 134.8, 137.8, $140.8(\mathrm{Ar}-$ C), 166.4 (CONH); LCMS (ES): $m / z 342.06(\mathrm{M}+\mathrm{H})^{+}$.

(6-Chloro-5-methyl-5,10-dihydrophenazin-1-yl)(morpholino) methanone (8k). Appearance: light green gummy; yield: 82\%; ${ }^{1} \mathrm{H}$ NMR (400 MHz, DMSO-d 6 ): $\delta$ ppm $3.22\left(3 \mathrm{H}, \mathrm{s}, \mathrm{N}-\mathrm{CH}_{3}\right), 3.35-$ $3.45\left(4 \mathrm{H}, \mathrm{m}, \mathrm{N}-\mathrm{CH}_{2}\right), 3.48-3.70\left(4 \mathrm{H}, \mathrm{m}, \mathrm{O}-\mathrm{CH}_{2}\right), 6.59-6.64(1 \mathrm{H}$, $\mathrm{m}, \mathrm{Ar}-\mathrm{H}), 6.65-6.76(5 \mathrm{H}, \mathrm{m}, \mathrm{Ar}-\mathrm{H}) 7.70(1 \mathrm{H}, \mathrm{s}, \mathrm{NH}) ;{ }^{13} \mathrm{C} \mathrm{NMR}$ (101 MHz, DMSO-d $\left.{ }_{6}\right): \delta$ ppm $28.8\left(2 \mathrm{C}, \mathrm{CONH}-\mathrm{CH}_{2}\right) 45.2(\mathrm{~N}-$ $\mathrm{CH}_{3}$ ), 65.9 (2C, O- $\mathrm{CH}_{2}$ ), 112.1, 118.9, 119.3, 120.5, 121.7, 122.3,
122.6, 124.2, 132.2, 135.0, 137.9, 140.7 (Ar-C), 166.7 (CONH); LCMS (ES): $m / z 344.06(\mathrm{M}+\mathrm{H})^{+}$.

6-Chloro-5-methyl- $N$-(pyridin-3-yl)-5,10-dihydrophenazine-1carboxamide (81). Appearance: dark yellow solid; yield: 77\%; MR: $204-206{ }^{\circ} \mathrm{C} ;{ }^{1} \mathrm{H}$ NMR (400 MHz, DMSO-d ${ }_{6}$ ): $\delta$ ppm 3.23-3.27 $\left(3 \mathrm{H}, \mathrm{m}, \mathrm{N}-\mathrm{CH}_{3}\right), 6.61(1 \mathrm{H}, \mathrm{dd}, J=7.23,1.97 \mathrm{~Hz}, \mathrm{Ar}-\mathrm{H}), 6.67-6.88$ $(4 \mathrm{H}, \mathrm{m}, \mathrm{Ar}-\mathrm{H}), 7.28-7.35(1 \mathrm{H}, \mathrm{m}, \mathrm{Ar}-\mathrm{H}), 7.37-7.44(1 \mathrm{H}, \mathrm{m}, \mathrm{Ar}-$ $\mathrm{H}), 8.11$ (1H, ddd, $J=8.33,2.63,1.53 \mathrm{~Hz}, \mathrm{Ar}-\mathrm{H}), 8.32(1 \mathrm{H}, \mathrm{dd}, J=$ 4.71, $1.42 \mathrm{~Hz}, \mathrm{Ar}-\mathrm{H}), 8.87$ (1H, d, $J=2.19 \mathrm{~Hz}, \mathrm{Ar}-\mathrm{H}), 9.20(1 \mathrm{H}, \mathrm{s}$, $\mathrm{NH}), 10.34(1 \mathrm{H}, \mathrm{s}, \mathrm{CONH}) ;{ }^{13} \mathrm{C}$ NMR (101 MHz, DMSO-d 6 ): $\delta$ ppm $45.3\left(\mathrm{~N}-\mathrm{CH}_{3}\right), 112.5,114.3,119.7,121.2,122.3,122.5$, 122.9, 123.3, 124.3, 128.0, 132.2, 135.2, 138.3, 139.5, 139.7, 142.5, 144.7 (Ar-C), 167.0 (CONH); LCMS (ES): $m / z 351.01$ (M + $\mathrm{H}^{+}{ }^{+}$; FT-IR (KBr) $\nu_{\max } 3448(\mathrm{NH}), 2923,1650(\mathrm{CONH}), 1472,1278$ (Ar-Cl), $708 \mathrm{~cm}^{-1}$.

6-Chloro- $\mathrm{N}$-(4-chloro-3-methoxyphenyl)-5-methyl-5,10-dihydrophenazine-1-carboxamide (8m). Appearance: dark yellow solid; yield: $82 \%$; MR: $166-168{ }^{\circ} \mathrm{C} ;{ }^{1} \mathrm{H}$ NMR (400 MHz, DMSO-d $\left.{ }_{6}\right): \delta$ ppm $3.25\left(3 \mathrm{H}, \mathrm{s}, \mathrm{N}-\mathrm{CH}_{3}\right), 3.85\left(3 \mathrm{H}, \mathrm{s}, \mathrm{O}-\mathrm{CH}_{3}\right), 6.61(1 \mathrm{H}, \mathrm{dd}, J=7.23$, $1.75 \mathrm{~Hz}, \mathrm{Ar}-\mathrm{H}), 6.69-6.85$ (4H, m, Ar-H), 7.29 (1H, dd, $J=7.89$, $1.10 \mathrm{~Hz}, \mathrm{Ar}-\mathrm{H}), 7.38$ (2H, m, Ar-H), 7.57 (1H, s, Ar-H), $9.18(1 \mathrm{H}, \mathrm{s}$, $\mathrm{NH}), 10.24$ (1H, s, CONH); ${ }^{13} \mathrm{C}$ NMR (101 MHz, DMSO-d 6 ): $\delta$ ppm $45.2\left(\mathrm{~N}-\mathrm{CH}_{3}\right), 55.8\left(\mathrm{O}-\mathrm{CH}_{3}\right), 105.5,112.5,113.5,114.7,115.5$, 119.6, 121.1, 122.2, 122.5, 122.9, 124.3, 129.4, 132.2, 138.3, 138.8, 139.6 (2C) (Ar-C), 154.2 (Ar-C-OCH $\left.{ }_{3}\right), 166.6$ (CONH); LCMS (ES): $m / z 413.03(\mathrm{M})^{+}$; FT-IR (KBr) $\nu_{\max } 3331,2923,1633,1594,1489$, 1277 (Ar-Cl), $744 \mathrm{~cm}^{-1}$.

6-Chloro-5-methyl-5,10-dihydrophenazine-1-carboxamide (8n). Appearance: yellow solid; yield: 65\%; MR: $192-194{ }^{\circ} \mathrm{C} ;{ }^{1} \mathrm{H}$ NMR (400 MHz, DMSO-d $\left.{ }_{6}\right): \delta$ ppm $3.22\left(3 \mathrm{H}, \mathrm{s}, \mathrm{NCH}_{3}\right), 6.49(1 \mathrm{H}$, $\mathrm{dd}, J=6.58,2.63 \mathrm{~Hz}, \mathrm{Ar}-\mathrm{H}), 6.55-6.83(4 \mathrm{H}, \mathrm{m}, \mathrm{Ar}-\mathrm{H}), 7.21(1 \mathrm{H}$, $\mathrm{dd}, J=8.00,1.21 \mathrm{~Hz}, \mathrm{Ar}-\mathrm{H}), 7.40(1 \mathrm{H}, \mathrm{br}$ s, CONH$), 7.97(1 \mathrm{H}$, br s, CONH), 10.01 (1H, s, NH); ${ }^{13} \mathrm{C}$ NMR (101 MHz, DMSO-d 6 ): $\delta$ ppm $45.2\left(\mathrm{~N}-\mathrm{CH}_{3}\right), 112.1,113.1,119.4,120.8,122.3,122.5$, 122.7, 124.4, 132.1, 138.2, 139.7, 140.3 (Ar-C), $170.2\left(\mathrm{CONH}_{2}\right)$; LCMS (ES): $m / z 273.09(\mathrm{M}+\mathrm{H})^{+}$; FT-IR (KBr) $\nu_{\max } 3460\left(\mathrm{NH}_{2}\right)$, $3326(\mathrm{NH}), 2923,1637$ (CONH), 1615, 1456, 1276 (Ar-Cl), $756 \mathrm{~cm}^{-1}$; HR-MS (ESI): $\mathrm{m} / z$ calcd for $\mathrm{C}_{14} \mathrm{H}_{12} \mathrm{ClN}_{3} \mathrm{O}\left([\mathrm{M}+\mathrm{H}]^{+}\right)$: 274.0747 found: 274.0742 .

\section{Biology}

Cell and culture conditions. The MCF-7 (breast cancer), A549 (lung cancer) and DU145 (prostate cancer) cell lines (ATCC) were maintained as a continuous culture in the Dulbecco's Modified Eagle's Medium (DMEM; Sigma-Aldrich, Inc.), supplemented with $10 \%$ fetal bovine serum (FBS; Himedia, Mumbai, India), $100 \mathrm{U} \mathrm{mL}^{-1}$ penicillin, and $100 \mu \mathrm{g} \mathrm{mL}$ streptomycin. The cells were grown at $37^{\circ} \mathrm{C}$ under the humidified atmosphere of $5 \% \mathrm{CO}_{2}$.

In vitro anticancer activity assessment. The cells were maintained in DMEM supplemented with 10\% FBS under the humidified atmosphere of $5 \% \mathrm{CO}_{2}$ at $37{ }^{\circ} \mathrm{C}$. Then, the cells were seeded in 96-well plates at the density of 10000 cells per well and incubated for $24 \mathrm{~h}$ to allow cell attachment. After this, the cells were treated with test compounds at $0.1,1,10,100 \mu \mathrm{M}$ concentration (all the test compounds were tested below their 
cytotoxic $\left(\mathrm{CTC}_{50}\right)$ concentrations $\left(\mathrm{CTC}_{50}>200 \mu \mathrm{M}\right)$ obtained against Vero cell lines). After $24 \mathrm{~h}$ treatment and incubation period, fresh DMEM containing MTT $\left(250 \mu \mathrm{g} \mathrm{mL}{ }^{-1}\right)$ was added to replace the medium, and again, the cells were incubated for an additional $3 \mathrm{~h}$. MTT was aspirated, and DMSO was added to dissolve the formazan crystals. Absorbance was measured at $570 \mathrm{~nm}$ using a micro plate reader (Infinite ${ }^{\circledR} 200$ Pro-Tecan, Switzerland).

Effect on cell cycle. The distribution of cells at different phases of the cell cycle was analysed using flow cytometry. Briefly, the cells were seeded in 6-well plates at the density of 1 $\times 105$ cells per well and incubated for $24 \mathrm{~h}$. Cells were then treated with $\mathbf{8 a}, \mathbf{8 1}$ and nocodazole $(5 \mu \mathrm{M})$ for $48 \mathrm{~h}$ to determine their effect on the cell cycle. After treatment, the cells were washed with PBS, harvested using trypsin EDTA, fixed in ice cold ethanol $(70 \%)$ and stored overnight at $2-8{ }^{\circ} \mathrm{C}$. The fixed cells were pelleted, resuspended and treated with a staining solution containing propidium iodide, RNAse and Triton $\mathrm{X}$ for $30 \mathrm{~min}$ at $37{ }^{\circ} \mathrm{C}$ to stain the nuclei and get rid of RNA. Herein, 10000 events were analyzed after doublet discrimination module using a flow cytometer (DAKO CYTOMATION, Beckman Coulter, Brea, CA). The Summit Software was used to analyse the histogram.

Western blotting. RIPA buffer (comprising $20 \mathrm{mM} \mathrm{NaH}_{2} \mathrm{PO}_{4}$, $50 \mathrm{mM}$ NaF, 2 mM EDTA, $150 \mathrm{mM} \mathrm{NaCl}$, 1\% deoxycholic acid, and $0.1 \%$ SDS, pH 7.2) was used to prepare whole cell lysates for Western blot analysis. Protease inhibitor cocktail (Sigma Aldrich, Mumbai) was used for the Western blot analysis. The protein $(40 \mathrm{mg}$ ) was taken and resolved using 10\% sodium dodecyl sulfate-polyacrylamide gel electrophoresis (SDS-PAGE). Antibodies against tubulin, cyclin-B1 and CDK1 were obtained from Santa cruz biotech, and horseradish peroxidaseconjugated goat anti-rabbit IgG was used as a secondary antibody. This was later detected using chemiluminescence reagents.

Tubulin polymerization inhibition assay. In vitro inhibition of tubulin polymerization was studied using a fluorescencebased tubulin polymerization assay kit (BK011, Cytoskeleton, Inc.). The procedure was according to the manufacturer's protocol. The reaction mixture in a final volume of $10 \mu \mathrm{L}$ in PEM buffer ( $80 \mathrm{mM}$ PIPES, $0.5 \mathrm{mM}$ EGTA, $2 \mathrm{mM} \mathrm{MgCl}_{2}$, pH 6.9) in 384 well plates contained $2 \mathrm{mg} \mathrm{mL}^{-1}$ bovine brain tubulin, 10 $\mu \mathrm{M}$ fluorescent reporter, and $1 \mathrm{mM}$ GTP in the presence or absence of test compounds at $37{ }^{\circ} \mathrm{C}$. Tubulin polymerization was observed by monitoring the fluorescence enhancement due to the incorporation of a fluorescence reporter into the microtubules as the polymerization proceeded. Fluorescence emission at $420 \mathrm{~nm}$ (excitation wavelength of $360 \mathrm{~nm}$ ) was measured for $1 \mathrm{~h}$ at $1 \mathrm{~min}$ intervals using a multimode plate reader (Tecan Pro M200). Nocodazole was the positive control used under similar experimental conditions. The $\mathrm{IC}_{50}$ values against tubulin polymerization were calculated by pre-incubating the test compounds with tubulin at five different concentrations.

Immunohistochemistry. Cells were seeded on a glass cover slip and incubated for $24 \mathrm{~h}$ in the presence or absence of test compounds $(5 \mu \mathrm{M})$. Cells grown on cover slips were fixed in $3.5 \%$ formaldehyde in phosphate-buffered saline (PBS) ( $\mathrm{pH} 7.4$ ) for 10 minutes at room temperature. Cells were permeabilized for 6 minutes in PBS containing 0.5\% Triton X-100 (Sigma) and $0.05 \%$ Tween-20 (Sigma). The permeabilized cells were blocked with $2 \%$ BSA (Sigma) in PBS for $1 \mathrm{~h}$. Later, the cells were incubated with a primary antibody for tubulin obtained from Sigma at a 1:200 dilution in a blocking solution for $4 \mathrm{~h}$ at room temperature. Subsequently, the antibodies were removed, and the cells were washed three times with PBS. Cells were then incubated with the FITC-labeled anti-mouse secondary antibody (1:500) for $1 \mathrm{~h}$ at room temperature. The cells were washed three times with PBS and mounted in a medium containing DAPI. Images were obtained using the Olympus confocal microscope.

\section{Conclusions}

In conclusion, a set of novel dermacozine-1-carboxamides (8a8n) was synthesized and well characterized by ${ }^{1} \mathrm{H} \mathrm{NMR},{ }^{13} \mathrm{C}$ NMR, FT-IR, mass and HR-MS analysis. The synthesized compounds were subjected to in vitro cytotoxic activity tests against the selected cancer cell lines MCF7, A549 and DU145 by the MTT assay. The dermacozine derivatives $\mathbf{8 a}$ and $\mathbf{8 1}$ showed significant anticancer potential comparable to the standard drug paclitaxel, especially against the DU-145 cells. Mechanistic investigations showed that these molecules arrested the cell cycle at the G2/M phase by affecting Cdk1 and cyclin-B1. It was also found that these compounds effectively inhibited tubulin polymerization. Hence, these compounds have the potential to be anticancer agents.

\section{Conflicts of interest}

There are no conflicts to declare.

\section{Acknowledgements}

The authors are thankful to the GVK Biosciences Private Limited for providing financial support and encouragement. Support received from the analytical Department GVK Biosciences Private Limited and biological support received from the Department of Pharmacology, JSS College of Pharmacy, are acknowledged. S. K. S. S. Pindiprolu thanks the Indian Council of Medical Research (ICMR), New Delhi, for providing Senior Research Fellowship.

\section{References}

1 L. A. Torre, F. Bray, R. L. Siegel, J. Ferlay, J. Lortet-Tieulent and A. Jemal, Global cancer statistics, 2012, Ca-Cancer J. Clin., 2015, 65(2), 87-108.

2 F. Bray, A. Jemal, N. Grey, J. Ferlay and D. Forman, Global cancer transitions according to the human development index (2008-2030): a population-based study, Lancet Oncol., 2012, 13(8), 790-801.

3 F. Biemar and M. Foti, Global progress against cancerchallenges and opportunities, Cancer Biol. Med., 2013, $10(4), 183$. 
4 S. Vinogradov and $\mathrm{X}$. Wei, Cancer stem cells and drug resistance: the potential of nanomedicine, Nanomedicine, 2012, 7(4), 597-615.

5 N. HariNarayanaMoorthy, C. Karthikeyan and P. Trivedi, Synthesis, cytotoxic evaluation and in silico pharmacokinetic prediction of some benzo [a] phenazine-5sulfonic acid derivatives, Med. Chem., 2009, 5(6), 549-557.

6 J. B. Laursen and J. Nielsen, Phenazine natural products: biosynthesis, synthetic analogues, and biological activity, Chem. Rev., 2004, 104(3), 1663-1686.

7 N. HariNarayanaMoorthy, V. Pratheepa, M. J Ramos, V. Vasconcelos and P. A Fernandes, Fused aryl-phenazines: scaffold for the development of bioactive molecules, Curr. Drug Targets, 2014, 15(7), 681-688.

8 W. M. Abdel-Mageed, B. F. Milne, M. Wagner, M. Schumacher, P. Sandor, W. Pathom-aree,
M. Goodfellow, A. T. Bull, K. Horikoshi and R. Ebel, Dermacozines, a new phenazine family from deep-sea dermacocci isolated from a Mariana Trench sediment, Org. Biomol. Chem., 2010, 8(10), 2352-2362.

9 M. Schumacher, M. Kelkel, M. Dicato and M. Diederich, A survey of marine natural compounds and their derivatives with anti-cancer activity reported in 2010, Molecules, 2011, 16(7), 5629-5646.

10 V. R. Ghanta, A. Pasula, L. Soma and B. Raman, Synthetic studies on dermacozines: first synthesis of dermacozines A, B and C, ChemistrySelect, 2016, 1(6), 1296-1299.

11 R. Heald, S. Price, B. Safina, P. P. A. Savy, E. M. Seward, D. P. Sutherlin and B. Waszkowycz, US Pat. US20120202785 A1, 2012. 